\title{
THE TREATMENT OF TRACHOMA*
}

BY

\author{
E. O. MARKS
}

BRISBANE

Mr. ArNold Sorsby's article on the treatment of trachoma in the February (1945) number is of the utmost interest to all who have to deal with the disease, and should give rise to a wide discussion. of the subject. In the hopes of such a discussion the following is contributed.

Over the last twenty-five years in Brisbane, at the Hospital for Sick Children and at the Wilson School Ophthalmic Hostel I have had the care of trachomatous children who come from the dry inland areas of Western Queensland where trachoma is prevalent. In those areas the dryness of the atmosphere, the dust, and the glare combine to form very irritating conditions for the conjunctivae, with a consequent common irritative conjunctivitis. Flies are very bad at some seasons, and epidemics of acute conjunctivitis are then common, especially in the less hygienic sections of the community. Follicular conjunctivitis and spring catarrh are as common there as elsewhere, and there is trachoma. However, most people in our " West " have lids and conjunctiva which compare well with those of dwellers in the more humid portions of the state, where trachoma is rare.

The first difficulty in any particular case is to decide whether the child has trachoma or one of the other varieties of conjunctivitis. In a typical case with characteristic signs all would be agreed on the diagnosis, but there are many more milder cases of chronic. conjunctivitis with somewhat roughened or velvety lids and varying degrees of thickening and varying amount or character of "granulations" in which the diagnosis can only be a matter of pious opinion on which experienced practitioners could reasonably disagree. I have seen many cases called trachoma by others in which I was confident the diagnosis was incorrect, and some in which the rapid recovery showed my own diagnosis to have been at fault. Most that I had regarded as "doubtful " trachoma showed by their progress that the doubt was justified.

In $1919 \mathrm{I}$ had the privilege one day of going with the late $\mathrm{Mr}$. Treacher Collins to see the Trachoma school at Swanley. From what I remember seeing then, most of the cases were mild and many of them would now make me doubt the certainty of the diagnosis. I can remember hearing a discussion about that time between two senior men at Moorfields as to whether or not a patient

* Received for publication, October 3, 1945. 
had trachoma and they decided to refer the case to Treacher Collins for decision.

This is all mentioned to emphasise the difficulty of diagnosis, and that the results of treatment of trachoma must in the first case depend on the standard of diagnosis and in the second case on the standard of cure, a matter of no less difficulty.

It is an old medical adage that, where there are many cures for a disease, it is either incurable or gets well itself. The cures for trachoma have been legion, does the adage apply? Since individual patients differ in the severity of the disease, in their resistance to it, in their response to treatment, and since also there may be a climatic, a seasonal, a racial or a geographical variation in its virulence, it is very difficult to draw satisfactory conclusions from the results of any particular treatment. There is also a fallacy not always borne in mind that a rapid improvement usually takes place in the first few weeks in an institution no matter what treatment is given, due no doubt to the improved general and ocular hygiene and diet.

In an endeavour to determine the relative merits of different local treatments I have at various times tried running tests of about five cases, treating the right eye one way and the left another in all five, choosing cases in which the two eyes appeared to be equally affected. This differential treatment was usually continued for three months or more. With perhaps the exception of the sulphonamide drugs my results fully confirmed the old adage. It does not matter what one applies locally, apart from lavage to keep the eye clean. Time and the general health are the cure, particularly time. It is years since I have painted a lid with silver nitrate or used copper sulphate. Milder things are every bit as good or better, being possibly. less harmful and certainly less unpleasant for the patient. Expression, where there was anything to express, seemed to make an immediate improvement but did not hasten the final cure.

My impression of the sulphonamide drugs is that, administered orally they are wonderful in dealing with the secondary infections but do not deal with the trachoma. They seem less efficient in local application. Prontosil and soluseptasine as drops did not seem to have much effect but sulphanilamide powder which remains in or clings about the eye for a long time does seem to benefit many though not all eyes, in comparison with the other eye as a control. But it is not a miracle worker. War conditions have latterly interrupted the supply of patients, and we have not had any severe cases to justify the use of penicillin since that drug has been available. The absence of these severe cases gives rise to the hope that the virulence, if not the prevalence, of the disease is diminishing.

Generally, my impression is that the milder the treatment of 
trachoma the better, and most children for some time have only had boracic lavage followed by a drop of $\frac{1}{2}$ per cent. zinc sulphate. The latter is perhaps a pandering to convention. The case for which the Wilson Hostel received the most gratitude was a small girl from central Australia who had been under treatment for a long period in hospitals in two of the southern capitals. When she arrived she had photophobia and blepharospasm and it was very difficult to see her cornea which had pannus and some ulceration. She was so miserable and unhappy that I said not to worry her for a few'days with anything but boracic lavage and atropine. She improved so rapidly and continuously that at no time was other treatment desirable, and boracic was all she ever got. Whether the child had an idiosyncrasy to drugs previously used, or whether she happened to come at the time she was going to get well in any case, the fact remained that she actually did wonderfully well with simple boracic lavage and the absence of chemical irritants. That was before the advent of sulphonamides.

To conclude, the main object of this communication is to enquire if others have tried the experiment of treating the two eves differently, and if so, their findings.

\section{SCHISTOSOMIASIS OF THE CONJUNCTIVA*, BX \\ GAMIL BADIR \\ ASSISTANT PATHOLOGIST, MEMORIAL OPHTHALMIC \\ LABORATORY, GIZA, CAIRO, EGYPT}

Schistosomiasis of the conjunctiva, as any extraperineal schistosomiasis, is very rare in relation to the big number of patients affected with bilharzia in Egypt.

In 1944, only one case of bilharziasis of the conjunctiva was examined pathologically at the Memorial Ophthalmic Laboratory.

In 1945, up to August, only one case (the present one) has been examined pathologically at the laboratory.

This relative rarity may be due to one of two reasons or to both :-

1. Infection with bilharzia through the conjunctiva is actuallv exceptional.

2. Bilharzial affection of the conjunctiva passes unnoticed by the patient until cured concomitantly with the urinary affection under specific treatment.

The first case of schistosomiasis of the conjunctiva observed was that of Sobhy Bey in 1927. The patient was a boy aged 8 years.

* Received for publication, December 6, 1945. 